\title{
Calcinose enzoótica em ruminantes no Brasil Central ${ }^{1}$
}

\author{
Karla M.R. Guedes ${ }^{2 *}$, Edson M. Colodel ${ }^{3}$, Márcio B. Castro ${ }^{4}$, Marcos A. Souza ${ }^{3}$, Laura \\ P. Arruda ${ }^{3}$, Daniela M. Dianezi ${ }^{5}$, José Renato J. Borges ${ }^{4}$ e Franklin Riet-Correa ${ }^{6}$
}

\begin{abstract}
Guedes K.M.R., Colodel E.M., Castro M.B. Souza M.A., Arruda L.P., Dianezi D.M., Borges J.R.J. \& Riet-Correa F. 2011. [Enzootic calcinosis in ruminants in Central Brazil.] Calcinose enzoótica em ruminantes no Brasil Central. Pesquisa Veterinária Brasileira 31(8):643-648. Laboratório de Patologia Veterinária, Universidade de Brasília, Av. L4 Norte, Cx. Postal 4508, Brasília, DF 70910-970, Brazil. E-mail: kmrgkarla@yahoo.com.br

Enzootic calcinosis is a disease characterized by mineralization of soft tissues, osteopetrosis, hypercalcemia and hyperphosphatemia. From 2004 to 2010, 86 cases of enzootic calcinosis were diagnosed in 42 farms in the states of Mato Grosso, Goias, Minas Gerais and Tocantins, and in the Federal District. The pastures were inspected in 33 farms, observing that in 32 outbreaks the disease occurred in degraded pastures invaded with different weeds. Previously known calcinogenic plants were not present. The disease was diagnosed in sheep in 19 farms, in cattle in 17 farms, in goats in five farms, and in sheep and goats in one farm. Adult animals were more affected; but the disease also was observed in lactating animals. The disease occurred all over the year, but most outbreaks were diagnosed during the rainy season. Serum Ca and P concentrations determined monthly in two sheep flocks were significantly higher during the rainy season. Main clinical signs were progressive emaciation followed by cachexia, and stiff gait with flexion of the fore limbs. Gross findings were mineralization of the arteries, cardiac valves, lungs, and kidneys. Histological findings were arterial mineralization, mainly in the medial layer with cartilaginous metaplasia and colagenous deposition between smooth muscle fibers. It is suggested that the disease is caused by an unknown calcinogenic weed present in degraded pastures.
\end{abstract}

INDEX TERMS: Enzootic calcinosis, ruminants, arterial mineralization, calcinogenic plants.

RESUMO.- A calcinose enzoótica é uma enfermidade caracterizada por mineralização de artérias e tecidos moles, osteopetrose, hipercalcemia e hiperfosfatemia. Neste trabalho descreve-se uma calcinose enzoótica em ruminantes no Mato Grosso, Goiás, Minas Gerais, Tocantins e no Distrito Federal, em campos onde não foi encontrada nenhuma das plantas calcinogênicas conhecidas. Os primeiros casos foram diagnosticados em 2004, e até 2010 foram necropsiados 86 casos da

\footnotetext{
${ }^{1}$ Recebido em 11 de março de 2011. Aceito para publicação em 4 de abril de 2011.

${ }^{2}$ Laboratório de Patologia Veterinária, Universidade de Brasília, Av. L4 Norte, Cx. Postal 4508, Brasília, DF 70910- 970, Brazil. * Autor para correspondência: kmrgkarla@yahoo.com.br

${ }^{3}$ Hospital Veterinário, Universidade Federal do Mato Grosso (UFMT), Av. Fernando Correia da Costa 2367, Cuiabá, MT, 78060-900, Brasil.

${ }^{4}$ Hospital Veterinário, Universidade de Brasília, Via L4 Norte, Brasília, DF 70910-970, Brasil.

${ }^{5}$ Secretaria de Estado de Agricultura, Pecuária e Abastecimento, SAIN, Parque Rural Edifício Sede s/n, Brasília, DF 70620-000.

${ }^{6}$ Hospital Veterinário, Universidade Federal de Campina Grande, Centro de Saúde e Tecnologia Rural, Cx. Postas 64, Patos, PB 58700-970, Brasil.
}

doença provenientes de 42 propriedades. Trinta e três propriedades foram visitadas, e em 32 os pastos eram caracterizados por moderada a acentuada degradação e invasão por plantas daninhas. A doença foi diagnosticada em ovinos em 19 fazendas, em bovinos em 17, em caprinos em 5 e em uma fazenda foram afetados tanto caprinos quanto ovinos. Animais adultos foram mais acometidos, mas a doença foi observada, também, em animais lactentes. A enfermidade foi observada durante todo o ano, mas a maioria dos surtos ocorreu nos meses de maior índice pluviométrico. Em duas fazendas foram determinados, mensalmente, os níveis séricos de Ca e P observando-se uma elevação significativa dos mesmos durante o período de chuvas. Os principais sinais clínicos observados foram de emagrecimento progressivo, caquexia e flexão de membros anteriores, com andar rígido. As principais lesões macroscópicas e histológicas foram de mineralização das artérias, valvas cardíacas, pulmões e rins. Sugere-se que a doença é provocada por uma planta calcinogênica ainda desconhecida. Mesmo sem conhecer a causa da calcinose recomenda-se evitar o pastejo de ruminantes em áreas degradadas e reformar pastagens degradadas. 
TERMOS DE INDEXAÇ̃̃O: Calcinose enzoótica, ruminantes, mineralização arterial, plantas calcinogênicas.

\section{INTRODUÇÃO}

A calcinose enzoótica é uma doença caracterizada por hipercalcemia, osteopetrose, calcificação dos tecidos moles e redução na produtividade dos rebanhos. No Brasil são conhecidas duas plantas que causam calcinose enzoótica: (1) Solanum glaucophyllum (= S. malacoxylon) que causa uma doença conhecida popularmente como "espichamento" em bovinos e bubalinos no Pantanal Matogrossense (Döbereiner et al. 1971, Santos et al. 2009), e (2) Nierembergia veitchii que causa a doença em ovinos no Rio Grande do Sul (Riet-Correa et al. 1987). Plantas responsáveis pelo surgimento da doença em outros países incluem Solanum glaucophyllum na Argentina (Carrillo \& Worker 1967) e no Uruguai (Riet-Correa et al. 1975), Nierembergia rivularis no Uruguai (Garcia y Santos et al. 2011), Trisetum flavescens na Alemanha (Dirksen et al. 1970), Solanum. torvum na Nova Guiné (Copland 1975) e Cestrum diurnum nos Estados Unidos (Krook et al. 1975) e Cuba (Durand et al. 1999).

Desde 2004, vem sendo diagnosticada uma doença de ruminantes caracterizada por calcificação de artérias e tecidos moles, nos estados de Minas Gerais, Goiás, Tocantins, Mato Grosso e Distrito Federal. Os animais afetados apresentam emagrecimento progressivo, que não regride mesmo quando o rebanho recebe suplementação. Diante disso, o objetivo desse trabalho foi identificar as características epidemiológicas, clínicas e anatomopatológicas da calcinose enzoótica que ocorre no Brasil Central, bem como tentar identificar sua etiologia e formas de controle da doença, minimizando as perdas econômicas provocadas pela mesma nos rebanhos de ruminantes.

\section{MATERIAL E MÉTODOS}

Foram estudadas 42 propriedades onde havia casos de calcinose enzoótica diagnosticados no Laboratório de Patologia Veterinária da Universidade de Brasília (LPV/UnB) e do LPV da Universidade Federal do Mato Grosso (UFMT), entre os anos de 2004 e 2010. Foram levantados os dados referentes à região de ocorrência, espécie acometida, número de animais doentes e mortos pela doença, idade e sexo dos animais, época de ocorrência da enfermidade, sinais clínicos e achados macroscópicos e histopatológicos.

Foram avaliados os níveis pluviométricos do Estado de Goiás e do Distrito Federal, entre os anos de 2004 e 2010. Os dados foram coletados no site do Instituto Nacional de Meteorologia (INMET www.inmet.gov.br), a partir das estações 83376-Pirenópolis (Goiás) e 83377-Brasília (Distrito Federal) e posteriormente foi obtido o valor médio mensal de chuvas nos anos estudados.

Em dois rebanhos de ovinos com casos de calcinose enzoótica, um no Distrito Federal e outro em Goiás, foi feita análise dos níveis de cálcio $(\mathrm{Ca})$ e fósforo $(\mathrm{P})$ séricos durante sete e oito meses, de 2008 a 2009. Para isso foram coletadas amostras de sangue de 20 ovinos de cada rebanho, uma vez por mês. 0 sangue foi coletado em tubo a vácuo de $9 \mathrm{ml}$, sem anticoagulante e as amostras foram então centrifugados a 2800 rotações por minuto (rpm) durante cinco minutos. Os testes foram realizados no LPV/UnB utilizando kits comerciais (Cálcio Liquiforme e Fósforo da Labtest ${ }^{\circledR}$ ), em medidor semi-automático (Bio-Plus $2000^{\circledR}$ ). Os níveis de Ca e P para ovinos foram comparados com os valores descritos por Kaneko (2008). 0 teste $\mathrm{t}$ de Student foi utilizado para comparar os níveis de Ca e P entre os rebanhos estudados.
De todos os animais necropsiados foram coletados órgãos das cavidades torácica e abdominal, além de sistema nervoso central. De dez ovinos foi coletada também tireóide.

Todos os fragmentos foram fixados em formol a 10\% tamponado, clivados e processados rotineiramente para coloração de hematoxilina-eosina (HE). Fragmentos de pulmão e artéria aorta foram processados para as colorações de Von Kossa para cálcio, Sirius Red para colágeno, Verhoeff para fibras elásticas e Tricrômico de Gomori para músculo liso (Hewitson \& Darby 2010).

\section{RESULTADOS}

\section{Epidemiologia e sinais clínicos}

Oitenta e seis animais foram necropsiados nas quarenta e duas propriedades estudadas pelos Laboratórios de Patologia Veterinária da UnB e UFMT entre os anos de 2004 e 2010. Algumas informações epidemiológicas importantes estão dispostas no Quadro 1.

Dos 86 ruminantes necropsiados 56 eram ovinos, 20 bovinos e 10 caprinos. Em 19 propriedades foram afetados ovinos, em 17 bovinos, em 5 caprinos e em 1 criavam-se caprinos e ovinos e as duas espécies foram acometidas. A maioria dos animais tinha entre 1 e 9 anos de idade, com alguns casos diagnosticados em ovinos com 3 a 8 meses de idade. Quanto ao sexo, a maioria dos animais necropsiados em todas as espécies era de fêmeas.

A mortalidade variou de 0,02\% a 70\% (Quadro 1). Quanto à distribuição geográfica dos casos de calcinose enzoótica, 19 foram no Mato Grosso, 7 no Distrito Federal, 6 em Goiás, 3 em Minas Gerais e 1 em Tocantins. A localização de 6 propriedades não foi identificada no histórico clínico.

Casos de calcinose enzoótica foram diagnosticados durante todo o ano, em maior número nos meses de janeiro, fevereiro e março. Não houve nenhum diagnóstico no mês de outubro. A maioria dos surtos ocorreu em meses de altos índices pluviométricos na região, principalmente no mês de janeiro.

Trinta e três propriedades foram visitadas para investigação dos surtos, e em trinta e duas observou-se a ocorrência de pastos moderada a acentuadamente degradados, com intensa invasão por plantas daninhas (Fig.1) que eram consu-

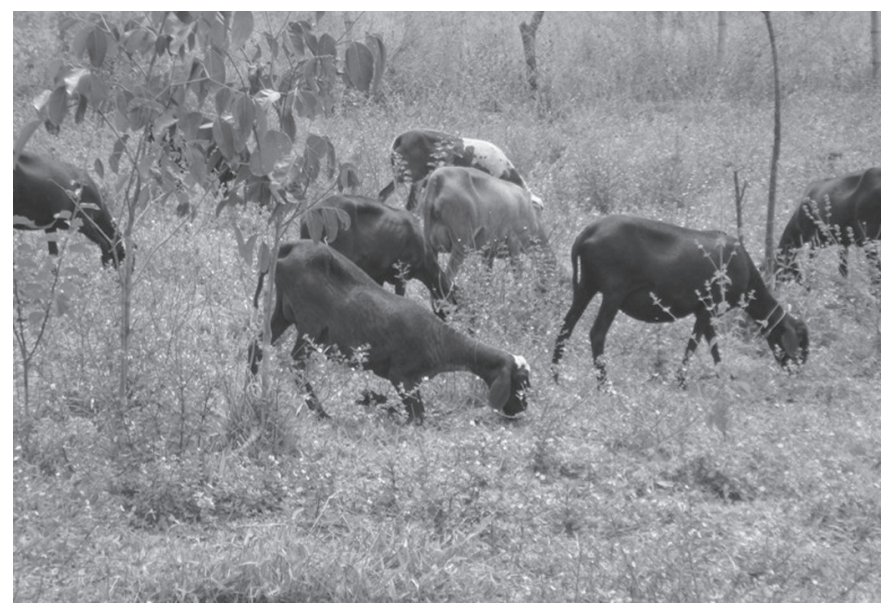

Fig.1. Ovinos de propriedade no município de Sobradinho, Distrito Federal, pastejando em área moderadamente invadida por plantas daninhas. No primeiro plano observa-se animal com calcinose enzoótica apresentando flexão dos membros anteriores, sinal clínico relacionado à doença. 
Quadro 1.- Descrição das propriedades estudadas, com dados sobre espécie e raça, número de animais no rebanho, animais afetados pela calcinose enzoótica, número de necropsiados e época de ocorrência da doença

\begin{tabular}{|c|c|c|c|c|c|}
\hline Espécie & Raça & Rebanho $^{\mathrm{a}}$ & $\begin{array}{c}\text { Animais mortos }{ }^{\mathrm{b}} / \\
\text { mortalidade (\%) }\end{array}$ & Localização & $\begin{array}{c}\text { Mês/ano primeiro } \\
\text { diagnóstico }\end{array}$ \\
\hline Bovino & Holandês & 100 & $70(70 \%)$ & Flores de Goiás, GO & Maio 2004 \\
\hline Ovino & Santa Inês & 220 & $45(20,45 \%)$ & Poconé, MT & Março 2005 \\
\hline Ovino & Santa Inês & 270 & $30(11,11 \%)$ & Alto Paraguai, MT & Maio 2005 \\
\hline Bovino & Nelore & 780 & $2(0,25 \%)$ & Rondonópolis, MT & Dezembro 2005 \\
\hline Ovino & Santa Inês & 300 & $70(23,33 \%)$ & Nova Brazilandia, MT & Janeiro 2006 \\
\hline Bovino & Nelore & 70 & $2(2,85 \%)$ & Poconé, MT & Janeiro 2006 \\
\hline Bovino & SRD & 30 & $12(40 \%)$ & São José do Povo, MT & Janeiro 2006 \\
\hline Bovino & Nelore & 50 & $1(2 \%)$ & São José do Povo, MT & Janeiro 2006 \\
\hline Bovino & SRD & 120 & $4(3,33 \%)$ & São José do Povo, MT & Janeiro 2006 \\
\hline Bovino & Girolanda & 45 & $4(8,88 \%)$ & Rondonópolis, MT & Janeiro 2006 \\
\hline Ovino & Santa Inês & 450 & $70(15,55 \%)$ & Santo Antônio de Leverger, MT & Fevereiro 2006 \\
\hline Ovino & Santa Inês & 80 & $12(15 \%)$ & Cuibá, MT & Fevereiro 2006 \\
\hline Ovino & Santa Inês & 240 & $10(4,16 \%)$ & Paracatu, MG & Março 2006 \\
\hline Bovino & $\mathrm{Ni}$ & 40 & $01(2,5 \%)$ & Paranoá, DF & Agosto 2006 \\
\hline Caprino & $\mathrm{Ni}$ & 300 & $01(0,33 \%)$ & Cocalzinho de Goiás, GO & Agosto 2006 \\
\hline Ovino & Santa Inês & 110 & $10(9,09 \%)$ & São Miguel do Araguaia, GO & Agosto 2006 \\
\hline Ovino & Santa Inês & 148 & $20(13,51 \%)$ & Santo Antônio do Descoberto, GO & Setembro 2006 \\
\hline Bovino & SRD & 40 & $2(5 \%)$ & São José do Povo, MT & Janeiro 2007 \\
\hline Ovino & Dorper & 230 & $2(0,86 \%)$ & Cuiabá, MT & Janeiro 2007 \\
\hline Ovino & Sana Inês & 180 & $17(9,44)$ & Nobres, MT & Janeiro 2007 \\
\hline Ovino & Santa Inês & 55 & $1(1,81 \%)$ & Padre Bernardo, GO & Fevereiro 2007 \\
\hline Bovino & Girolando & $\mathrm{Ni}$ & 1 & $\mathrm{Ni}$ & Fevereiro 2007 \\
\hline Ovino & Santa Inês & 35 & $1(2,85 \%)$ & Paracatu, MG & Fevereiro 2007 \\
\hline Ovino & SRD & 215 & $85(39,53 \%)$ & Araguaçu, T0 & Março 2007 \\
\hline Ovino & Santa Inês & 47 & $8(17,02 \%)$ & São Sebastião, DF & Junho 2007 \\
\hline Bovino & Holandês & $\mathrm{Ni}$ & 1 & $\mathrm{Ni}$ & Julho 2007 \\
\hline Ovino & Santa Inês & $\mathrm{Ni}$ & 1 & $\mathrm{Ni}$ & Julho 2007 \\
\hline Bovino & Girolando & $\mathrm{Ni}$ & 1 & Brazlândia, DF & Janeiro 2008 \\
\hline Bovino & Girolando & $\mathrm{Ni}$ & 1 & Brasília, DF & Março 2008 \\
\hline Caprino & Saanen & 60 & $1(1,66 \%)$ & Santo Antônio de Leverger, MT & Janeiro 2008 \\
\hline Caprino & Saanen & 46 & $5(10,86 \%)$ & Santo Antônio de Leverger, MT & Janeiro 2008 \\
\hline Caprino & Saanen & 70 & $12(17,14 \%)$ & Nova Olimpia, MT & Janeiro 2008 \\
\hline Bovino & Girolando & $\mathrm{Ni}$ & 1 & Paranoá, DF & Março 2008 \\
\hline Bovino & Nelore & 4380 & $1(0,02 \%)$ & Formosa, GO & Abril 2008 \\
\hline Bovino & SRD & $\mathrm{Ni}$ & 1 & $\mathrm{Ni}$ & Junho 2008 \\
\hline Ovino & SRD & $\mathrm{Ni}$ & 1 & Unaí, MG & Novembro 2008 \\
\hline Ovino & SRD & 140 & $23(16,42 \%)$ & Paranatinga, MT & Fevereiro 2009 \\
\hline Ovino & Santa Inês & 700 & $90(12,85 \%)$ & Paranatinga, MT & Fevereiro 2009 \\
\hline Ovino & Santa Inês & 101 & $2(1,98 \%)$ & Sobradinho, DF & Fevereiro 2009 \\
\hline Caprino e Ovino & SRD e Santa Inês & Ni e 70 & $30,42 \%)$ & Sobradinho, DF & Março 2009 \\
\hline Caprino & Anglo Nubiano & $\mathrm{Ni}$ & 1 & $\mathrm{Ni}$ & Abril 2009 \\
\hline Bovino & Girolando & $\mathrm{Ni}$ & 1 & $\mathrm{Ni}$ & Agosto 2009 \\
\hline
\end{tabular}

${ }^{\mathrm{a}}$ Número de animais no rebanho, ${ }^{\mathrm{b}}$ número de animais mortos devido à calcinose enzoótica, $\mathrm{SRD}=$ sem raça definida, $\mathrm{Ni}=$ não informado.

midas pelos rebanhos em abundância, principalmente nos meses de maiores índices pluviométricos, quando havia plantas verdes em maior quantidade.

Os sinais clínicos mais característicos foram o emagrecimento progressivo, seguido por caquexia, e andar rígido, geralmente com os membros anteriores ligeiramente flexionados. Alguns ovinos andavam apoiando a articulação do joelho (Fig.1).

\section{Análise de Ca e $P$ séricos e níveis pluviométricos}

Entre os meses de outubro a dezembro de 2008 os ovinos avaliados apresentaram aumento significativo $(\mathrm{p} \leq 0,05)$ nos níveis de cálcio, em relação ao valor máximo de referência para a espécie (11,5-12,8mg/dl) (Kaneko 2008). Na fazenda de Goias os valores de Ca do rebanho avaliado foram de $14,11 \pm 2,9 \mathrm{mg} / \mathrm{dl}$ em outubro; $13,95 \pm 3,2 \mathrm{mg} / \mathrm{dl}$ em novembro e $17,02 \pm 2,7 \mathrm{mg} / \mathrm{dl}$ em dezembro. Entre os 20 ovinos avaliados
$75 \%$ apresentaram aumento dos níveis de Ca no mês de outubro, $65 \%$ em novembro e $100 \%$ em dezembro. No Distrito Federal o rebanho avaliado apresentou os maiores níveis de Ca nos mesmos meses, sendo eles respectivamente $13,10 \pm 3,4 \mathrm{mg} / \mathrm{dl} ; 13,10 \pm 1,6 \mathrm{mg} / \mathrm{dl}$ e 16,56 $\pm 2,3 \mathrm{mg} / \mathrm{dl}$. Entre os 20 ovinos avaliados, $40 \%$ apresentaram aumento nos níveis de Ca em outubro, 50\% em novembro e 95\% em dezembro. No mês de novembro, $60 \%$ dos ovinos do rebanho de Goiás ultrapassaram o valor máximo de referência dos níveis de $\mathrm{P}$ (5,0-7,3 mg/dl) (Kaneko 2008), atingindo 8,08 $\pm 2,7 \mathrm{mg} / \mathrm{dl}$. Não houve diferença significativa $(\mathrm{p} \geq 0,05)$ nos níveis de Ca e P entre os dois rebanhos estudados. Na Figura 2 apresentam-se os índices pluviométricos médios mensais no estado de Goiás e no Distrito Federal entre janeiro de 2008 e janeiro de 2009. Nas duas localidades as chuvas têm início no mês de setembro, mas os maiores índices são atingidos entre os meses de novembro e março, quando são ultrapassados os $200 \mathrm{~mm}^{3}$ por mês. 


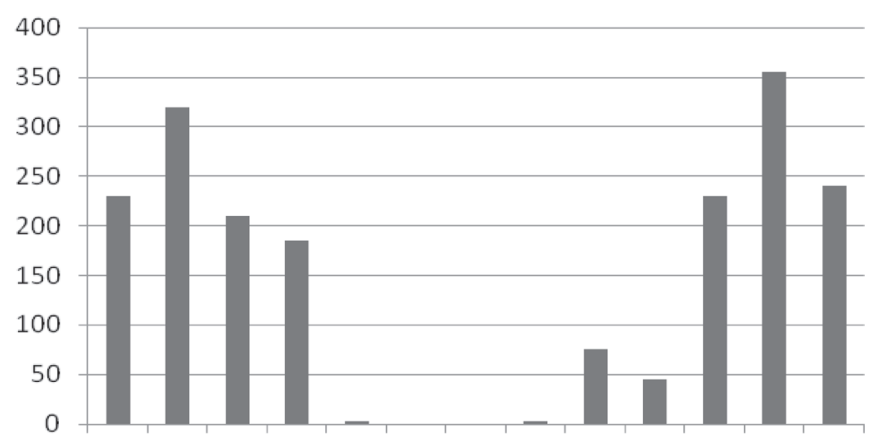

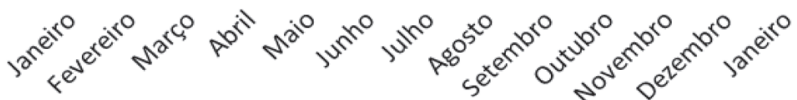

Fig.2. Níveis pluviométricos médios, em milímetros cúbicos $\left(\mathrm{mm}^{3}\right)$, do Distrito Federal e Goiás, de janeiro de 2008 a janeiro de 2009.

\section{Patologia}

No coração, a principal alteração foi a mineralização das valvas átrio-ventriculares (VAV). As áreas de mineralização, tanto no corpo quanto nas bordas das cúspides, tinham o aspecto de placas irregulares, esbranquiçadas e mais firmes que o normal. A lesão foi observada principalmente na VAV es-

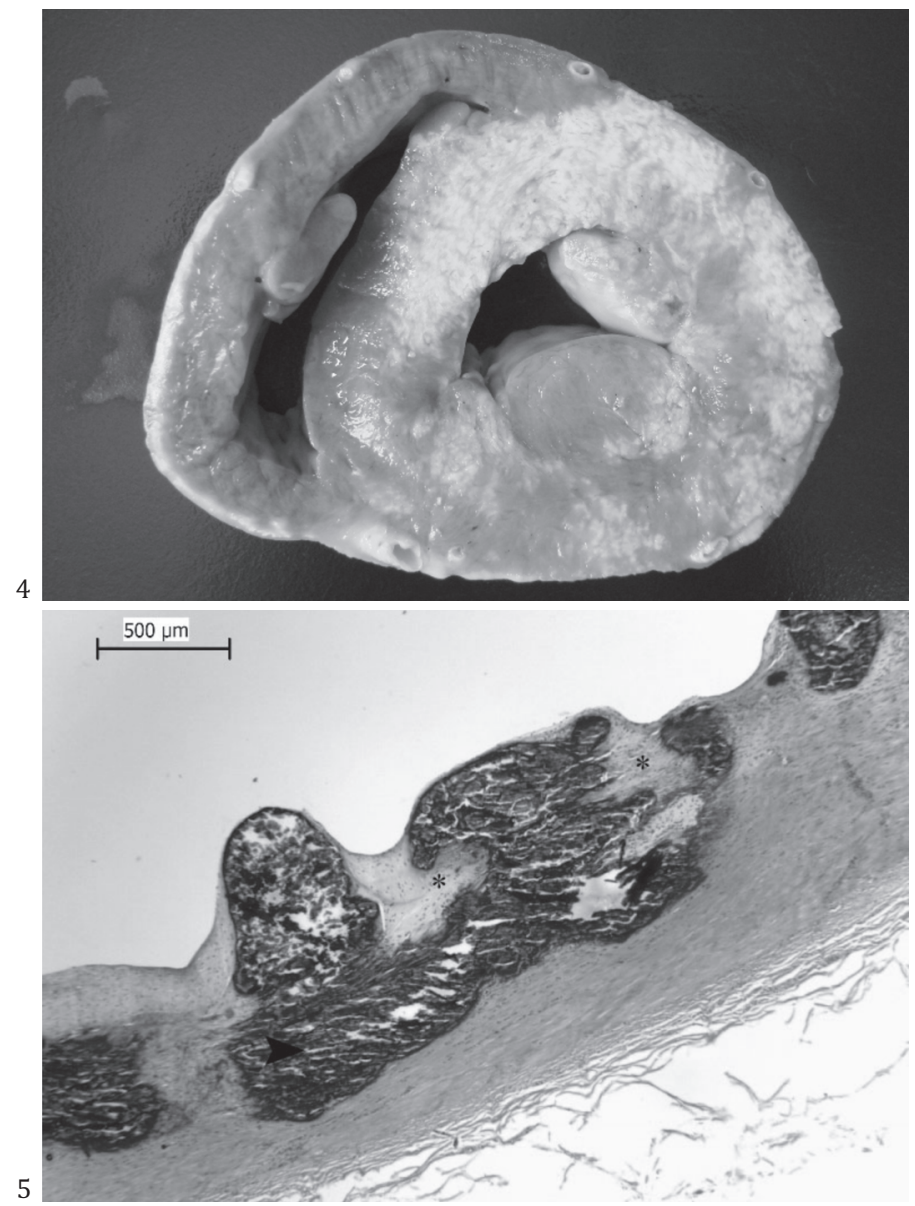

Fig.3. Extensas áreas pálidas mineralizadas na parede do ventrículo cardíaco esquerdo de ovino com calcinose enzoótica.

Fig.5. Placas mineralizadas basofílica nas camadas média e íntima (cabeça de seta) e áreas de metaplasia cartilaginosa (asterisco) na aorta de ovino com calcinose enzoótica. HE, obj.4x. querda, havendo também alteração na VAV direita e na valva semilunar. Em vários animais havia calcificação na parede de átrio e ventrículo (Fig.3) e no músculo papilar caracterizadas por áreas esbranquiçadas granulares. Havia ainda focos de mineralização nas cordas tendíneas.

Nas artérias as lesões foram caracterizadas pela presença na superfície luminal de placas esbranquiçadas, elevadas, firmes e enrijecidas (Fig. 4). Os principais locais de mineralização na artéria aorta foram na porção cranial seguida pela porção média e caudal. Mineralização da artéria tronco-pulmonar foi observada em alguns ovinos, todas na área de inserção ao coração. Outras artérias acometidas foram carótida em toda sua extensão, artéria mesentérica, artéria sacralmediana, artérias do tronco braquicefálico e artérias ilíacas externa e interna.

Numerosos animais apresentavam mineralização pulmonar caracterizada por áreas granulares, esbranquiçadas e mais firmes que o normal na borda dos lobos, ou grandes áreas de consistência inelástica (borrachenta) e pálidas, provocando abaulamento do parênquima. Em um caprino observou-se o pulmão com extensas áreas firmes e ossificadas, principalmente ao redor de brônquios.

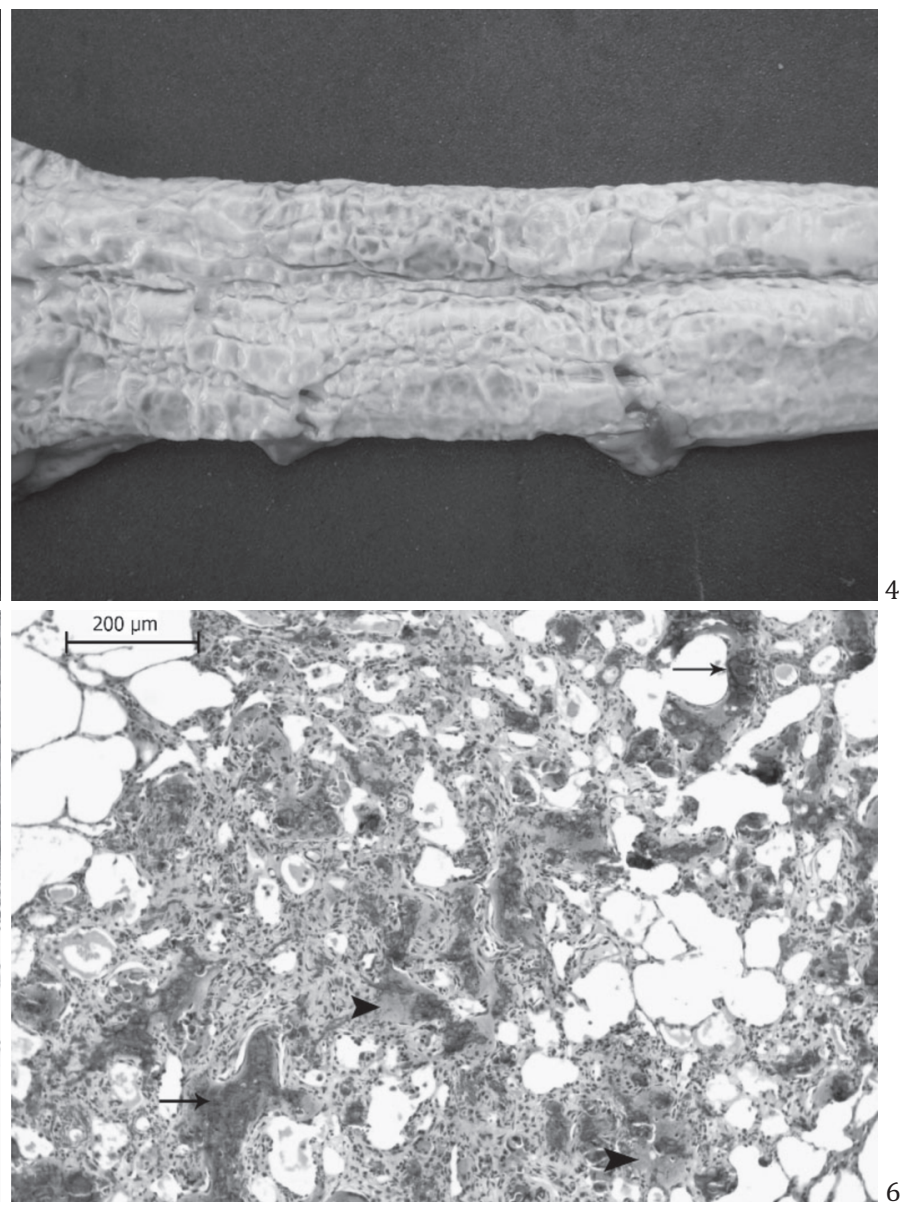

Fig.4. Placas firmes e mineralizadas na média da aorta de ovino com calcinose enzoótica.

Fig.6. Focos basofílicos mineralizados nos septos alveolares (seta) e áreas de proliferação de colágeno (cabeça de seta) no pulmão de ovino com calcinose enzoótica. HE, obj.10x. 
Em alguns animais havia mineralização renal visível macroscopicamente. Os focos mineralizados eram caracterizados por pontos ou raias esbranquiçados e de consistência arenosa tanto na região cortical quanto na medular. Em alguns animais a mineralização era caracterizada pela presença de uma faixa esbranquiçada e firme na região de junção córticomedular.

Na tireóide de um ovino havia foco de coloração enegrecida na região central, compatível com melanose e em outro se observaram manchas esbranquiçadas de cerca de 0,3 mm.

Focos de mineralização foram vistos esporadicamente em grandes vasos do parênquima hepático, no diafragma e na cartilagem aritenoide e epiglote. Alguns dos ovinos necropsiados apresentavam também quadro grave de anemia e alta carga de parasitismo por Haemonchus contortus.

As alterações histopatológicas nas fibras musculares cardíacas eram caracterizadas por irregularidade, fragmentação das fibras e deposição de grânulos basofílicos (mineralização) intracitoplasmáticos. Número moderado de animais apresentava mineralização de artérias coronárias e do miocárdio. Em dois ovinos observou-se a presença de trabéculas ósseas e tecido hematopoiético na região de inserção da artéria aorta ao coração.

Histologicamente as lesões arteriais eram caracterizadas pela formação de placas basofílicas, algumas com aspecto cristalizado, com fragmentação das fibras, principalmente na túnica média (Fig. 5). Em meio às áreas mineralizadas e próximo a elas havia focos de proliferação de células semelhantes a condroblastos (metaplasia cartilaginosa) e de células semelhantes à fibroblastos. Nessas áreas de lesão mais acentuada havia também mineralização e proliferação na túnica íntima. Mineralização da túnica íntima foi vista em quase todos os animais estudados e todos eles apresentavam mineralização acentuada a moderada da túnica média. Irregularidade das fibras também foi vista com frequência. Metaplasia cartilaginosa foi observada em quantidade moderada de animais, principalmente ovinos. Alterações vistas em menor quantidade foram a presença de substância eosinofílica entre as fibras e infiltração de macrófagos nas áreas de mineralização e irregularidade de fibras elásticas. A coloração de Von Kossa demonstrou focos de deposição de pigmento enegrecido, caracterizando acúmulo de minerais (cálcio) na camada média das artérias. A coloração de Verhoeff demonstrou que na artéria aorta as áreas de mineralização eram observadas em meio às fibras elásticas, e na coloração de Tricrômico de Gomori observou-se a deposição acentuada de colágeno em meio às fibras de músculo liso, havendo perda dessas fibras em algumas áreas.

Histologicamente nos pulmões havia mineralização moderada a acentuada dos septos interalveolares que variava de áreas discretas a focos extensos (Fig.6). Na coloração de Von Kossa observaram-se vários focos de deposição de pigmento de coloração enegrecida, caracterizando o acúmulo de cálcio nas paredes dos alvéolos. Em quantidade moderada dos animais os alvéolos apresentavam suas paredes rompidas nas áreas de mineralização, e outros tinham apenas espessamento da parede alveolar. Havia mineralização também das cartilagens bronquiais em alguns animais. Na parede de veias e artérias pulmonares de alguns ovinos foram vistos também focos de mineralização discreta a moderada. Em poucas arteríolas havia deposição mineral na luz dos vasos. Em alguns animais havia infiltração de macrófagos próximos às áreas de mineralização, e em outros havia discreta mineralização da camada muscular de brônquios. Próximo às áreas de mineralização era possível observar também focos de proliferação de fibroblastos. No pulmão de um caprino e um ovino observou-se a presença de mineralização acentuada, com formação de trabéculas ósseas em meio ao parênquima.

Nos rins as alterações eram de mineralização de artérias e túbulos. Mineralização tubular foi vista tanto na região cortical quanto na medular. Na maioria dos casos de mineralização tubular, essa era localizada apenas nas células do epitélio, mas em alguns casos havia acúmulo de material mineralizado também na luz dos túbulos. Na maioria dos animais avaliados havia mineralização das camadas íntima e média das artérias.

Quantidade discreta a moderada dos animais avaliados apresentou algum grau de hiperplasia das células $C$ da tireóide. A hiperplasia era caracterizada pela presença de proliferação de células com citoplasma claro em meio aos folículos tireoidianos. Em um ovino observou-se, na região central da glândula, quantidade moderada de células redondas, com citoplasma abundante e com pigmento marrom acastanhado no interior, compatível com melanose.

\section{DISCUSSÃO}

A calcinose enzoótica diagnosticada em ruminantes no Brasil Central até o momento tem sua etiologia ainda desconhecida; entretanto, as características epidemiológicas, clínicas e patológicas da doença sugerem que a mesma seja causada por uma planta calcinogênica ainda não identificada. Durante o período de estudo foram testadas experimentalmente, em ovinos e coelhos, 29 espécies diferentes de plantas invasoras, todas com resultados negativos (Guedes et al. 2011). Novos experimentos com as diferentes plantas presentes nas áreas onde ocorre a doença são necessários para a identificação da provável espécie calcinogênica. Um fato comum observado em 32 das 33 fazendas estudadas é a ocorrência da enfermidade em áreas de pastagens degradadas, principalmente de Brachiaria spp., invadidos por plantas daninhas, o que alem de sugerir que nessas áreas ocorre alguma planta calcinogênica ainda desconhecida, alerta para a necessidade de evitar o pastoreio de ruminantes nessas áreas.

A elevação dos níveis séricos de Ca e P nos meses de maior índice pluviométrico sugere que a doença ocorre principalmente nesse período e que a elevação da calcemia e fosfatemia seja causada pela ingestão da provável planta calcinogênica quando a mesma está em brotação. Em conseqüência, estudos para determinar a presença de plantas calcinogênicas deverão ser feitos, preferencialmente, no início da estação chuvosa. Apesar de que doença é, aparentemente, sazonal, casos da mesma foram diagnosticados durante todo o ano, devido, provavelmente, ao caráter crônico da enfermidade e a irreversibilidade das lesões.

Em consequência de que o principal sinal clínico é o emagrecimento progressivo, ou o baixo escore corporal e pouco ganho de peso, que pode ser confundido com outras doenças 
ou com problemas nutricionais, é difícil estimar a morbidade da enfermidade, mas em alguns rebanhos a mortalidade foi alta chegando a 70\% (Quadro 1). Os dados apresentados neste trabalho mostram a importância econômica da doença, diagnosticada em numerosas oportunidades em extensas áreas de diferentes Estados do Brasil Central e em três espécies diferentes. As principais perdas pareceriam ser causadas pelo baixo desempenho dos rebanhos, tanto no ganho de peso quanto nos índices reprodutivos, mas a morte de animais, os gastos extras com contratação de médicos veterinários, a compra de medicamentos e a necessidade de alimentação suplementar, entre outros, são também importantes.

A maioria dos animais afetados tinha mais de um ano de idade, mas casos da doença foram relatados também em animais jovens, com 3 a 8 meses de idade, alguns lactentes. Não há descrições anteriores realizadas no Brasil da enfermidade em animais nessa faixa etária. Tanto nos casos de intoxicação de ovinos por N. veitchii (Rissi et al. 2007, 2009), quanto nos casos descritos de intoxicação de bovinos por $S$. glaucophyllum (Döbereiner et al. 1971) a doença é descrita em animais adultos. Búfalos intoxicados naturalmente por $S$. glaucophyllum tinham todos de 3 a 6 anos de idade (Santos et al. 2009).

Os sinais clínicos, as alterações nos níveis séricos de Ca e $\mathrm{P}$ e as lesões macroscópicas e histológicas encontradas foram semelhantes às descritas em outras calcinoses enzooóticas causadas por diferentes plantas descritas anteriormente na literatura (Carrillo \& Worker 1967, Döbereiner et al. 1971, Krook et al. 1975, Riet-Correa et al 1987, Santos et al. 2009, Garcia y Santos et al. 2011).

Conclui-se que a calcinose enzoótica que afeta ovinos, bovinos e caprinos no Brasil Central é uma doença de importância econômica, causada provavelmente por uma planta tóxica, que ocorre em pastagens degradadas. Até não ser determinada a planta que causa a doença á única forma de diminuir os prejuízos econômicos causados pela enfermidade é evitar a degradação das áreas de pastejo e refazer as pastagens degradadas.

Agradecimentos.- Ao Instituto Nacional de Ciência e Tecnologia para o Controle das Intoxicações por Plantas (CNPq, Proc.573534/2008-0) pelo suporte financeiro e a todos os colegas médicos veterinários que ajudaram na realização dessa pesquisa.

\section{REFERÊNCIAS}

Carrillo B.J. \& Worker N.A. 1967. Enteque seco: arteriosclerosis y calcificación metastática de origen tóxico em animales a pastoreo. Revta Invest. Agrop. 4(2):9-29.

Copland J.L. 1975. Enzootic calcinosis of cattle in Papua New Guinea. Aust. Vet. J. 51:326.

Dirksen G., Plank P., Spiess A., Hänichen T. \& Dämmrich K. 1970. Über eine enzootische kalzinose beim Rind. 1. Klinische Beobachtungen und Untersuchungen. Dtsch. Tierärztl. Wochenschr. 77:321-338.

Döbereiner J., Tokarnia C.H., Costa J.B.D., Campos J.L.E. \& Dayrel M.S. 1971. "Espichamento", intoxicação de bovinos por Solanum malacoxylon, no Pantanal do Mato Grosso. Pesq. Agropec. Bras. 6:91-117.

Durand R., Figueiredo J.M. \& Mendoza E. 1999. Intoxication in cattle from Cestrum diurnum. Vet. Hum. Toxicol. 41(1):26-27.

García y Santos C., Capelli A., Sosa S., Pérez W., Domínguez R., Pereira R., Bonino F., Goyen J.M. \& Alonso E. 2011. Enzootic calcinosis of sheep in Uruguay, p.448-451. In: Riet-Correa F., Pfister J., Schild A. L. \& Wierenga T. (Eds), Poisoning by Plants, Mycotoxins and related Toxins. CAB International, London.

Guedes K.M.R., Colodel E.M., Castro M.B., Mustafa V.S., Moraes D.D., Reis Jr J.L., Borges J.R.J., Boabaid F.M., Ubiali D., Arruda L.P. \& Riet-Correa F. 2011. Enzootic calcinosis in ruminants from Central Brazil, p.452-457. In: RietCorrea F., Pfister J., Schild A.L. \& Wierenga T. (Eds), Poisoning by Plants, Mycotoxins and related Toxins. CAB International, London.

Hewitson T.D. \& Darby I.A. 2010. Methods in molecular biology: Histology protocols. Humana Press, New York, NY. 229p.

Kaneko J.J., Harvey J.W. \& Bruss M.L. 2008. Clinical Biochemistry of Domestic Animal. Academic Press. $6^{\text {th }}$ ed. San Diego, CA. 904p.

Krook L., Wasserman R.H., McEntree K., Brokken T.D. \& Teigland M.B. 1975. Cestrum diurnum poisoning in Florida cattle. Cornell Vet. 65:557-575.

Riet-Correa F., Riet-Correa I. \& Bellagamba C. 1975. Calcificación metastásica enzoótica (enteque seco) en bovinos del Uruguay. Veterinaria, Uruguay, 12(60):15-23

Riet-Correa F., Schild A.L., Méndez M.C., Wasserman R. \& Krook L. 1987. Enzootic calcinosis in sheep caused by the ingestion of Nierembergia veitichii (Solanaceae). Pesq. Vet. Bras. 7(3):85-95.

Rissi D.R., Rech R.R., Pierezan F., Kommers G.D. \& Barros C.S.L. 2007. Intoxicação em ovinos por Nierembergia veitchii: observações em quatro surtos. Ciência Rural 37(5):1393-1398.

Rissi D.R., Brown C.C. \& Barros C.S.L. 2009. Chronic and acute clinical manifestation associated with systemic mineralization caused by ingestion of Nierembergia veitchii in sheep in southern Brazil. Small Rum. Res. 87:102-104

Santos C.E.P., Marques L.C., Figueiredo C., Borges D.C., Borges N.F. \& Assis C.J. 2009. Calcinose enzoótica em Bubalus bubalis no Pantanal Norte Matogrossense, Brasil. Anais VIII Congresso Brasileiro de Buiatria, Belo Horizonte, p.331-335. 